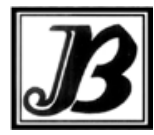

J. Bio-Sci. 26: 55-58, 2018

ISSN 1023-8654

http://www.banglajol.info/index.php/JBS/index

-Short communication

\title{
MICROBIAL INOCULANTS ON THREE MEDICINAL PLANTS OF THE LAMIACEAE, COLONIZED WITH ARBASCULAR MYCORRHIZAL FUNGUS
}

\author{
KP Gabriel1 ${ }^{*}$, T Yeasmin² and HC Lakshman ${ }^{3}$ \\ 1,3PG Department of Studies in Botany, Microbiology Laboratory, Karnataka University, Dharwad-580003, \\ Karnataka, India \\ 2Dept. of Biochemistry and Molecular Biology, University of Rajshahi, Rajshahi-6205, Bangladesh
}

Arbascular mycorrhizal (AM) fungal association plays an important role in the nutrient cycling through their microbial activity and their involvement in plant nutrient acquisition (Bethlefalvay et al. 1999). A wide spectrum of studies has been carried out on their ecology and their distribution, their effects on host physiology, biochemistry and genetics (Li et al. 2006). In the present study the roots of three medicinal plants were analyzed growing in experimental pots inoculated with fungi. Plant growth-promoting rhizobacteria (PGPR) and actinomycetes in order to evaluate AM fungal infection and colonization.

Pot experiment was carried out on Ocimum basilicum, O. sanctum, O. gratissimum in sandy loam soil. Presoaked seeds of the above medicinal plants were sown at $4.0 \mathrm{~cm}$ depths of the pot soil (soil characteristic are shown in Table 1). Surrounding rhizosphere of one week seedling plants were separately inoculated with $25.0 \mathrm{ml}$ culture of each phosphate solubilizing fungi PGPR bacteria i.e. Penicillium sp. [Dw B1], Penicillium sp. [Dw B4] Aspergillus sp. [Dw B2], Penicillium sp., Aspergillus sp. [Dw B3], and 7 phosphate solubilizing bacteria, Bacillus sp. [BGgd 20], Bacillus sp. [BEyr 22] Micrococcus sp. [Dsh 15], Micrococcus sp. [Hsh 18], Pseudomonas sp. [ Kyg 11], Arthrobacter sp. [Dsh 15], Serretia sp. [Kkg 9] and Azotobacter sp. [Gmg 16], Azotobacter sp. [Hvbd 7], Gluconobacter sp. [Rmv 10], Streptomyces sp. [Hu A1]. Watering through misting for 2 hours twice a day was done regularly. Hogland nutrient solution was added to each pot at $25 \mathrm{ml} /$ month. Finally, 120-day-old plant roots were taken out for analysis of AM colonization by following $\mathrm{KOH}$ digestion and trypan blue staining of $1 \mathrm{~cm}$ roots bits of each plant (Phillips and Hayman 1970, Kormanic and McGraw 1982). Microscopic observations for the presence of vesicles and arbuscules within the stained roots were recorded and per cent colonization was calculated.

*Author for correspondence: gkgary777@gmail.com; yeasmin_bio@ru.ac.bd 
Table1. Showing characteristics of soil used for experimental pots

\begin{tabular}{cc}
\hline Parameters & Mean value \\
\hline Coarse sand & $44 \%$ \\
Fine sand & $17 \%$ \\
Slit & $14 \%$ \\
Clay & $09 \%$ \\
Texture & Sandy clay \\
pH & 6.7 \\
Organic carbon & $0.28 \%$ \\
Available nitrogen & $142.7 \mathrm{~kg} / \mathrm{ha}$ \\
Available phosphate & $32.4 \mathrm{~kg} / \mathrm{ha}$ \\
Available potassium & $17.2 \mathrm{~kg} / \mathrm{ha}$ \\
\hline
\end{tabular}

Analysis of roots of different Ocimum sp. exhibited AM colonization. However, they differed in occurrence of colonization and their patterns. Since the experiment was carried out in natural and unsterile soil, uninoculated plants were also infected and colonized with least percent colonization (6.2\% to $11.4 \%)$ except for $O$. basilicum, $O$. sanctum (Table 2). Mycorrhizal inoculation with Arthrobacter do not infected with mycorrhizal roots of $O$. sanctum, similarly Gluconobacter $\mathrm{sp}$. Rmv10 with mycorrhizal roots of have not observed in the root colonization of $O$. basilicum, $O$. sanctum and $O$. gratissimum. A significant higher root colonization was recorded with the inoculation of mycorrhiza with treatment of Micrococcus sp. [H sh 18] (44\%) on Occimum basilicum (39\%) followed by Azotobacter sp. [Gmg 1] and Aspergillus sp. [Dw B2] (32\%). Higher per cent root colonization was observed in the roots of $O$. sanctum with treatment Azotobacter sp. [Hvbd 7], followed by the treatment of Bacillus sp. [BEyr 22]. The extra radical mycelium connects plants roots to the surrounding soil micro habitat increasing the soil volume explicated by host plants. Similarly, mycorrizhal hypae transport mineral nutrient over greater distances from depleted zones (Jakobsen 1995). And thus, under low nutrient conditions AM fungal colonized roots may have an enhanced uptake of relatively in mobile macro and micro nutrient (Subramanian and Charest 1999, Azcon et al. 2002). In addition, mycorrhizal roots often have not only increased length but also modified root architecture (Berta et al. 1995, Lakshman 1996). A limited range of colonization implies low level of potential and infectivity of indigenous AM fungi. In the present study $O$. gratissimum have lower colonization range from 12.2 to $28.2 \%$. It may also reflect the lower potential of plants towards AM fungi infection (Rahangdale and Gupta 1999). The observation of this study was supported by early works of (Lakshman 1998, Sabard et al. 2007, Dash and Gupta 2011). Hence it can be deduced that each plant has its own preference towards mycorrhization (Zaidi et al. 2003). Several environmental factors such as soil moisture, temperature, pH, nutrients and change in plant community composition can influence the AM fungal root colonization. 
Table 2. Screening of percent root colonization of tree Lamiaceae members for 90 days

\begin{tabular}{lccc}
\hline Treatment & O. basilicum & O. sanctum & O. gratissimum \\
\hline Control & $3.0 \pm 00$ & $1.2 \pm 1.0$ & $3.4 \pm 1.0$ \\
Pencillium sp. Dw B 1 & 0.0 & 1.0 & $17.6 \pm 1.0$ \\
Pencillium sp. Dw B 4 & $23.4 \pm 2.0$ & $17.6 \pm 1.0$ & $21.5 \pm 2.2$ \\
Aspergillus sp. Dw B 2 & $32.0 \pm 1.0$ & $28.1 \pm 1.0$ & $34.2 \pm 1.0$ \\
Aspergillus sp. DW B 3 & $18.4 \pm 2.0$ & $13.3 \pm 1.0$ & $13.2 \pm 2.1$ \\
Bacillus sp. BGgd 20 & $15.3 \pm 2.2$ & $17.1 \pm 0.0$ & $19.2 \pm 1.0$ \\
Bacillus sp. BE yr 22 & $13.2 \pm 1.2$ & $14.2 \pm 2.2$ & $12.5 \pm 1.0$ \\
Pseudomonas sp. Kyg 11 & $17.2 \pm 0.0$ & $16.3 \pm 3.1$ & $13.1 \pm 2.2$ \\
Serretia sp. Kkg 9 & $16.1 \pm 1.0$ & $14.2 \pm 1.1$ & $18.1 \pm 2.0$ \\
Azotobacter sp. Gmg 16 & $39.3 \pm 7.0$ & $31.4 \pm 2.0$ & $19.3 \pm 5.0$ \\
Azotobacter sp. Hvbd 7 & $32.5 \pm 0.0$ & $42.1 \pm 2.1$ & $17.4 \pm 2.0$ \\
Arthrobacter sp. Dsh 15 & $42.0 \pm 2.0$ & 0.0 & $15.3 \pm 5.2$ \\
Micrococcus sp. H sh 18 & $44.1 \pm 3.1$ & $9.8 \pm 1.0$ & $2.2 \pm 0.0$ \\
Micrococcus sp. & $11.6 \pm 1.0$ & $17.2 \pm 2.1$ & $13.4 \pm 3.0$ \\
Gluconobacter sp. Rmv 10 & 0.0 & 0.0 & $1.4 \pm 0.0$ \\
Streptomyces sp. HU A1 & $13.4 \pm 5.0$ & $12.2 \pm 2.0$ & $15.3 \pm 5.2$ \\
\hline
\end{tabular}

Each value 4 triplicates is the mean value of \pm standard error.

\section{Acknowledgement}

KPG and HCL are thankful to DST-SERB, India for financial support and sanctioning the Major Research Project "Experimental studies on the additive effect of PGPR and hydrolytic enzyme in Niger plants infected with AM fungi".

\section{References}

Azcon-Aguilar C, MC Jaizme-Vega and C Calvet (2002). The contribution of arbuscular mycorrhizal fungi for bioremediation. In: Mycorrhizal Technology in Agriculture. From Genes to Bioproducts, Gianinazzi S, Schuepp H, Barea JM and Haselwandter K (Eds.). Birkhauser Verlag Berlin, pp.187-197.

Berta G, Trotta A, Fusconi A, Hooker J, Munro M, Atkinson D, Giovannetti M, Morini S, Fortuna P, Tisserant B, Gianinazzi V, Pearson and Gianinazzi S (1995). Arbuscular mycorrhizal induced changes to plant growth and root system morphology in Prunus cerasifera L. Tree Physiology, 15: 281-293.

Bethlenfalvay GJ, Cantrell IC, Mihara KL and Schreiner RP (1999). Relationships between soil aggregation and mycorrhizae as in- fluenced by soil biota and nitrogen nutrition. Biology and Fertility of Soils, 28: 356-363.

Dash S and Gupta N (2011). Impact of microbial inoculants on AM colonization in tree legumes, Mycorrhiza News, 23(1): 12-13. 
Jakobsen I (1995). Transport of phosphorus and carbon in VA mycorrhizas. In: Mycorrhiza- Structure, function, molecular biology and biotechnology. Ed. Varma A and Hock B. Berlin: Springer Verlag, pp. 297-324.

Kormanic PP and McGraw AC (1982). Quantification of vesicular-arbuscular mycorrhizae in plant roots. In: Methods and Principles of Mycorrhizal Research, Ed. Schenck NC, pp. 37-45.

Lakshman HC (1996). VA mycorrhizal studies in some important timber tree species. PhD thesis, Karnatak University, Dharwad, India, pp. 255.

Lakshman HC (1998). Some central potential plants with VAM fungi and their use in revegetation programmes. Journal of Coastal Zone Management, 2: 189-196.

Li HY, Yang GD, Shu HR, Yang YT, Ye BX, Nishida I and Zheng CC (2006). Colonization by the arbuscular mycorrhizal fungus Glomus versiforme induces a defense response against the root-knot nematode Meloidogyne incognita in the grapevine (Vitis amurensis Rupr.), which includes transcriptional activation of the class III chitinase gene VCH3. Plant Cell Physiology, 47(1): 154-163.

Phillips JM and Hayman DS (1970). Improved procedure for daring roots and staining parasitic and vesicular arbuscular mycorrhizal fungi for rapid assessment of infection. Transactions of the British Mycological Society, 55: 158-160.

Rahangdale R and Gupta N (1999). Vesicular arbuscular association of biomass tree species in the tropical forest of Madhya Pradesh. Indian Journal of Forestry, 22(1): 62-65.

Sabarad A, Swamy GSI, Patil CP, Duragannavar MP and Patil PB (2007). Cumulative effect of arbuscular mycrorrhizal fungi, vermicompost and Trichoderma harzianum on bunch, finger characters, and yield of banana cv. Rajapuri (Musa AAB). Mycorrhiza News, 18(4): 20-22.

Subramanian KS and Charest C (1999). Acquisition of $\mathrm{N}$ by external hyphae of an arbuscular mycorrhizal fungus and its impact on physiological responses in maize under drought-stressed and well watered conditions. Mycorrhiza, 9: 6975.

Zaidi A, Khan MS and Amil M (2003). Interactive effect of rhizotrophic microorganisms on yield and nutrient uptake of chickpea (Cicer arietinum L.). European Journal of Agronomy, 19(1): 15-21. 